magnet with centimetre, gram, second and permeability of vacuum fundamental, the electrostatic with permittivity replacing permeability, and rationalized and subrationalized forms of each, the Gaussian mixed system with some quantities expressed in electromagnetic others in electrostatic units, the rationalized form of this, introduced by Heaviside and Lorentz, the Maxwell quadrant $\left(10^{9} \mathrm{~cm}.\right)$, $10^{-11}$ gram, second and permeability of vacuum, the Bennett and others, centimetre, $10^{7}$ gram, and a unit of permittivity of vacuum $=1 /\left(8.989 \times 10^{11}\right)$, the Giorgi, metre, kilogram, second and $10^{7}$ times the permeability of vacuum. The last three systems all have the ampere, volt and watt as units of current, potential and power respectively.

\section{Trend of Design of Electric Locomotives}

THE paper on the trend of the design of electric locomotives during the last ten years, read to the Institution of Electrical Engineers by C. E. Fairburn, the electrical engineer to the L.M.S. railway, is a valuable contribution to electric traction. He shows clearly that there is a growing demand for loco. motives of greater power and speed. This is due partly to the necessity of improving running schedules with heavier trains and of avoiding the higher cost of multiple operation. Fairly complete data are given of ten electric railways in eight different countries and from twelve manufacturing companies. To analyse them is difficult because the outlook and methods vary not only from country to country but also from railway to railway in the same country. In Austria, Germany, Switzerland and Sweden low-frequency alternating current is employed; in Belgium, Italy and Poland, 3,000 volts direct current; France, Holland, Japan and much of the British Empire, use 1,500 volts direct current. Three-phase systems seem to be making little progress. In Germany, the express locomotive of the German State Railways is of 4,150 horse-power. Recent Swiss locomotives have 8,630 horse-power and the articulated express locomotives of the Pennsylvania Railroad can supply 9,500 horse-power for a short period. General experience with high-power locomotives, in particular on the Pennsylvania Railroad, shows that even larger horse-powers are desirable, especially on lines carrying heavy traffic. It is definitely stated that the advantages of electric braking on long gradients lie more in the reduction of wear in the mechanical parts than in the value of the energy returned to the supply system. With high speeds it is advisable to retain mechanical brakes for emergency operation as this makes higher speeds possible with safety.

\section{Water Heating by Electricity}

AT a meeting of the Association of Supervising Electrical Engineers held in London on April 12, P. Honey discussed the technical aspects of water heating by electricity. Since two trades were involved, namely, plumbing and wiring, the question of responsibility for satisfactory working has to be considered. The retailer of the appliance has to take upon himself the responsibility of planning the installation and, with the co-operation of a hot-water fitter, make certain that the workmanship is good. The problems of the water authorities are similar, in some respects, to those of supply undertakings. Unlike electric supply they have not the stimulus of competition. As water for domestic purposes is rarely charged for by quantity, the most urgent need is to prevent waste. They have therefore insisted that the fittings and appliances should be in accordance with certain specifications. To eliminate 'peak' demands which would cause serious drop in water pressure, the use of feed cisterns is insisted on by many authorities to ensure a more even demand. The amount of storage water held in this way in the houses of consumers is a considerable fraction of the total stored by the authorities. Regulations, therefore, were issued which restricted the connexion of electric water heaters of the thermal storage type direct to the cold water main. For example, in London, no heater larger than three gallons must be connected in such a manner. Those of larger size must be fed from an adequate storage system. No water authority in Great Britain would permit the connexion of a pressure water heater direct to the cold mains in the way frequently done abroad. The cost of servicing electric water heaters of all kinds is not a serious item. The majority of the few electrical defects which occur are probably due to the thermostat and are not serious.

\section{Education in 1932-I934 in the United States}

THE United States Office of Education has recently published its "Biennial Survey of Education 19321934" (Washington: Government Printing Office. Pp. 1222. Price 1.10 dollars). The effects of the economic depression, which touched its lowest point in 1932, are reflected in many of the statistical tables. The total aggregate income for education from kindergarten upwards in 1933-34 was about 2,604 million dollars, of which huge sum more than five sixths represent income of publicly controlled institutions. Compared with the corresponding figures for 1931-32, there was a decrease of $15 \cdot 5$ per cent, and compared with those for 1929-30 a decrease of $22 \cdot 6$ per cent. It is noteworthy that the decrease was twice as heavy in privately controlled as in publicly controlled institutions from 1932 to 1934 , although it had been much lighter in the preceding biennium. Statistics of university enrolments which had risen continuously for many years showed a sharp drop after 1932. It is estimated that the percentage of boys and girls who on completion of their secondary school education entered a university or other institution for further education was in 1933 about 26. This is a high figure compared with the corresponding percentage in Great Britain, but it is low compared with the average percentage (44) of the years 1921-1929 in the United States.

\section{University College, London}

ITs recently issued annual report shows that this most cosmopolitan of all colleges in Great Britain numbered last year among its 3,284 students no fewer than 910 visitors from 52 countries outside the British Isles. By far the biggest contingent, 228, 
came from India. From Germany came 73, Scandinavian countries 47, Switzerland 30, France 25, Holland 21; from Australia 30, New Zealand 27, Canada and Newfoundland 45, the United States 43, South Africa 37, Egypt 26, Palestine 28, China 35. For some years past the College reports have directed attention to the increase in the number of postgraduate and research students. Last year these advanced students numbered 616 , and it is noteworthy that more than 40 per cent of them were from abroad, including 81 from India, 24 from Canada and Newfoundland, 23 from China, 22 from New Zealand, 18 from Australia, 18 from South Africa, 10 from the United States and 10 from Germany. A list of more than five hundred original papers and other publications from the various departments of the College in 1937 is appended to the report. A coloured plan shows graphically the growth of the College site and buildings since 1827 .

\section{Health of School Children}

THe annual report for 1936 of the chief medical officer of the Board of Education, Sir Arthur MacNalty, entitled "The Health of the School Child" (London: H.M. Stationery Office. 2s. 2d., postage included) states that, during the year in question, the nutrition of more than $1,700,000$ children was assessed with the result that $\mathbf{1 4 \cdot 6}$ per cent were regarded as excellent, 74.2 as normal, $10 \cdot 5$ as slightly subnormal and 0.7 as bad; these figures are substantially the same as those in the report for the previous year. Free school meals provided have increased from $87,000,000$ in $1935-36$ to more than $100,000,000$ in 1936-37. More than half the children who could receive milk either free or at half-price still fail to take it. Medical inspection and eyesight, care of the teeth, physical training and recreation and the national health campaign are some of the other subjects dealt with in this report.

\section{Netherlands Indies}

THE Colonial Institute of Amsterdam, which maintains a research department and an economic museum as well as an ethnographical department in conjunction with the Netherlands Pacific Institute, has published the first number of a new quarterly entitled Bulletin of the Colonial Institute of Amsterdam (18s. a year). The aim of the new publication is to give authoritative articles in English on various aspects of the Netherlands Indies. Only a small part of each number will be written in Dutch. Articles of scientific interest in the first number treat of malaria in the Netherlands Indies, social organizations of the peoples of Borneo, Celebes and the Moluceas, and air transport in the Pacific.

\section{Asbestos}

A RECENT publication of the Mineral Resources Department, Imperial Institute, is a monograph on asbestos by Mr. G. E. Howling (second edition. 2s.). The volume includes a discussion of occurrence, mining methods, uses, marketing and world production, and ends with a full bibliography.

\section{Universal Esperanto Congress}

ThE thirtieth Universal Esperanto Congress will be held in London on July 30-August 6, under the high patronage of H.R.H. the Duke of Connaught. The total membership of the Congress is expected to be about 1,500 , of whom some 1,300, representing twentyfive nationalities, had been enrolled at the beginning of June. The official proceedings will, as usual on these occasions, be carried on in the international language alone, no interpreters being employed either at the general meetings or at the sectional gatherings of specialists. Among the social features of the week will be two performances in Esperanto of "Eliza Comes to Stay" by members of the NeilsonTerry Guild of Dramatic Art, who have been learning the language for the purpose. It has been decided to hold next year's Congress at Bern, Switzerland.

\section{The Night Sky in July}

THE moon is full on July $12^{\mathrm{d}} 15 \cdot 1^{\mathrm{h}}$ and new on July $27^{d} 03 \cdot 9^{\text {h }}$ U.T. The only bright star to be occulted this month is $\lambda$ Piscium, the reappearance of which will be visible from Greenwich on July 18 at $2^{\mathrm{h}} 22 \cdot 4^{\mathrm{m}}$, at position angle $198^{\circ}$ from the north point of the moon's image. Lunar conjunctions with the planets occur as follows: with Jupiter on July $16^{\mathrm{d}} 7^{\mathrm{h}}$; with Saturn on July $20^{\mathrm{d}} 0^{\mathrm{h}}$; with Mercury on July $29^{\mathrm{d}} 5^{\mathrm{h}}$; and with Venus on July $30^{\mathrm{d}} 9^{\mathrm{h}}$. On July 26, Mercury is near Regulus, the minimum apparent separation (geocentric) being $0.9^{\circ}$; and on July $31^{\mathrm{d}} 7^{\mathrm{h}}$ Mercury is in conjunction with Neptune, the separation being $0 \cdot 4^{\circ}$. Venus is a bright evening star, setting about $1^{\mathrm{h}} 40^{\mathrm{m}}$ after the sun in mid-July. Jupiter and Saturn are both visible during the night, Jupiter, a very bright object, southing about $2 \frac{1}{2}^{\mathrm{h}}$ in the middle of the month and Saturn three hours later. The interesting phenomena (eclipses, transits, occultations) of the Jovian four inner satellites may be followed with the help of the table and diagram given on p. 613 of the Nautical Almanac for 1938 or of the table on p. 170 of Whitaker's Almanack. At $22^{\mathrm{h}}$ in mid-July, Vega is nearing the southern meridian and precedes the Milky Way. The bright star Deneb ( $\alpha$ Cygni) on the galactic equator marks the apex of the bifurcation of the Milky Way, one branch passing southwards through Serpens and Scorpio; the other through Aquila, Scutum and Sagittarius. Interesting objects for telescopic examination abound in this region, which is also the habitat of the novæ. The 6th magnitude double-star, 61 Cygni, was the first star to have its distance successfully measured one hundred years ago by Bessel, who made his measures with a heliometer. His results gave the star's distance as 640,000 times that of the earth-sun distance; modern measures give 680,000 times this unit.

\section{Announcements}

The Right Hon. Neville Chamberlain has been elected a fellow of the Royal Society under Statute 12, which provides for the election of persons who "either have rendered conspicuous service in the cause of science, or are such that their election would be of signal benefit to the Society". 